\title{
Obesity in Saudi children: a dangerous reality
}

\author{
S.S. Al-Dossary, P.E. Sarkis, ${ }^{1}$ A. Hassan, ${ }^{2}$ M. Ezz El Regal ${ }^{3}$ and A.E. Fouda ${ }^{3}$
}

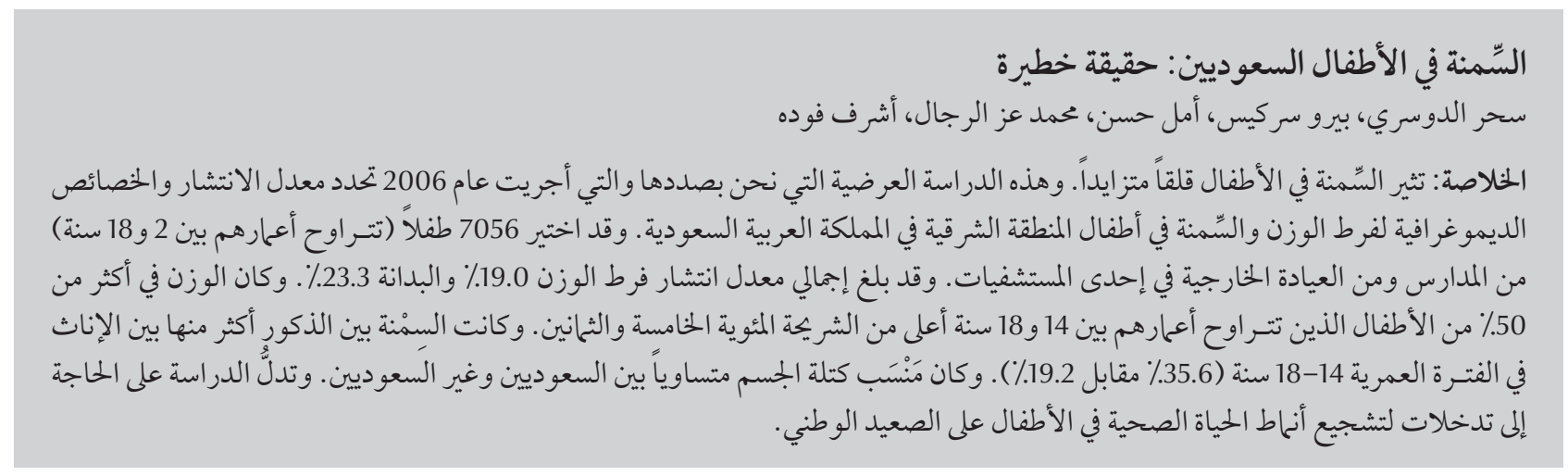

ABSTRACT Obesity among children is an increasing concern. This cross-sectional study in 2006 determined the prevalence and demographic characteristics of overweight and obesity in children in the Eastern province of Saudi Arabia. A total of 7056 children (aged 2-18 years) were selected from schools and the outpatient department of a hospital. The overall prevalence of overweight was $19.0 \%$ and of obesity was $23.3 \%$. More than $50 \%$ of children between 14 and 18 years had weight above the 85th percentile. More males than females were obese by ages $14-18$ years (35.6\% versus 19.2\%). Saudi and non-Saudi nationalities had the same distribution of body mass index. Interventions to encourage healthier lifestyles for children are needed at the national level.

\section{Obésité chez les enfants saoudiens : une réalité dangereuse}

RÉSUMÉ L'obésité chez les enfants suscite de plus en plus d'inquiétudes. Cette étude transversale réalisée en 2006 visait à déterminer la prévalence et les caractéristiques démographiques du surpoids et de l'obésité chez les enfants de la province orientale d'Arabie saoudite. Au total, 7056 enfants (âgés de 2 à 18 ans) ont été sélectionnés dans des établissements scolaires ou au service de consultation externe d'un hôpital. La prévalence globale du surpoids était de $19 \%$ et celle de l'obésité de 23,3\%. Plus de $50 \%$ des enfants âgés de 14 à 18 ans avaient un poids supérieur au $85^{\mathrm{e}}$ percentile. Entre 14 et 18 ans, le nombre de garçons obèses était supérieur à celui des filles (35,6 \% contre 19,2\%). La répartition de l'indice de masse corporelle était identique pour les Saoudiens et les non Saoudiens. Il est nécessaire de mettre en place au niveau national des interventions visant à encourager des modes de vie plus sains. 


\section{Introduction}

Towards the end of the 20th century, obesity was identified as a worldwide health care problem affecting the wellbeing of populations. Previously identified only as a problem of adult health, obesity among children is increasingly becoming a concern [1]. The Gulf region is not exempt. Surveys in a number of different areas and provinces have reported a high prevalence of overweight and obesity in Saudi children in all age groups [2,3]. Government and local authorities have implemented educational programmes to help weight reduction or prevention of obesity. Abnormal weight in children is still considered by experts to be caused by an imbalance between diet and habit, although a hormonal etiology is a diagnosis that needs to be excluded in children.

In order to add valid information about the weight status of children in our region, this study was conducted in the Eastern province of Saudi Arabia to determine the prevalence of overweight and obesity in children from the Eastern province of Saudi Arabia and to compare these prevalences with those of non-Saudi children living in Saudi Arabia.

\section{Methods}

This was a cross-sectional study conducted in Al-Khobar city, in the Eastern province of Saudi Arabia. Data collection started on January 2006 and continued for 6 months.

\section{Sample}

Our sample included 7056 children aged 2-18 years of Saudi or non-Saudi nationality enrolled from a school and from the outpatient department of a hospital.

Saad specialist hospital is a tertiary centre in the Eastern province. It is a private institution with a capacity of 600 beds, admitting patients from all socioeconomic classes. All paediatric consultations done during the period of study in the outpatients department ( $n$ $=9249)$ were collected from the electronic database. After excluding followup consultations and incomplete files, a total of 6237 files were evaluated and after excluding those aged $<2$ years ( $n=441$ cases), 5796 children were enrolled.

Saad schools for boys and girls are private institutions in the Al-Khobar region, Dammam, in the Eastern province. All 1260 students aged 6-17 years enrolled in the schools were included in the study, which is $10 \%$ of the total number of students in the private educational sector and $3 \%$ of the total (public and private) students of the AlKhobar-Dammam region [4].

Prior to enrolment a consent form was signed by the child's parent after an explanation of the aims and methods of the study.

\section{Data collection}

The internal validity of the study was ensured by the data collectors in both Saad schools and Saad specialist hospital. These were nurses who received training prior to data collection with special emphasis on standardizing the methods of measurement. Body weight and height of children were measured using a digital scanner. The instruments used were calibrated daily.

A data collection form was designed to gather data on: age, sex and nationality as well as measures of body weight and height. Body mass index (BMI) was calculated for each child according to the formula adopted internationally: BMI $=$ weight $(\mathrm{kg}) /$ height $(\mathrm{m})^{2}$ [5]. We used the Centers for Disease Control and Prevention (CDC) 2000 growth charts [6]. The children were classified into 3 weight categories: normal weight (BMI $<85$ th percentile for age and sex), overweight (BMI between 85th-95th percentiles) and obese (BMI > 95th percentile) $[7,8]$. Then percentile weight categories among the sample were studied by nationality, sex and age groups $(2-4,5-9,10-13$ and 14-18 years).

To ensure better generalization of the results, the data from patients presenting to the outpatients department of the hospital were compared with the data from school students to confirm that the distribution by age, sex and nationality was similar before pooling the data.

\section{Statistical analysis}

Data analysis was done using SPSS software, version 12, and the chi-squared test, Student $t$-test and analysis of variance (ANOVA). Statistical significance was set at $P<0.05$.

\section{Results}

The sample included 7056 children, mean age 8.7 (standard deviation 4.9) years. Males were $55.7 \%$ of the study children and females were 44.3\%. Most of the children were of Saudi nationality (79.4\%) while $20.6 \%$ were various nonSaudi nationalities.

Classification of the enrolled children according to BMI revealed that only $57.7 \%$ of them had normal weight for age and sex, while $19.0 \%$ were overweight and $23.3 \%$ obese (none of the children were underweight).

The rates of overweight and obesity increased progressively with age. The overall rate of obesity was significantly higher than the rate of overweight in all age groups $(P<0.05)$. A progressive rise in the rates of obesity and overweight were found with age from ages 5-9 years to $14-18$ years, peaking at age $10-13$ years $(20.2 \%$ and $28.0 \%$ for obesity and overweight respectively) (Table 2). At age 2-4 years the proportions of children who were normal weight, overweight and obese were $62.7 \%, 18.1 \%$ and $19.2 \%$ respectively. By age $14-18$ years the proportions were $53.0 \%, 20.0 \%$ and $27.0 \%$. 


\begin{tabular}{|c|c|c|c|c|c|c|c|c|c|}
\hline \multirow[t]{2}{*}{ Categories } & \multicolumn{2}{|c|}{$\begin{array}{l}\text { Normal weight } \\
(\text { BMI }<85 \%)\end{array}$} & \multicolumn{2}{|c|}{$\begin{array}{c}\text { Overweight } \\
\text { (BMI 85\%-95\%) }\end{array}$} & \multicolumn{2}{|c|}{$\begin{array}{c}\text { Obese } \\
(\mathrm{BMI}>\mathbf{9 5 \%})\end{array}$} & \multicolumn{2}{|c|}{ Total } & \multirow[t]{2}{*}{$P$-value } \\
\hline & No. & $\%$ & No. & $\%$ & No. & $\%$ & No. & $\begin{array}{c}\% \text { in } \\
\text { category }\end{array}$ & \\
\hline \multicolumn{10}{|l|}{ Sex } \\
\hline Male & 2185 & 55.6 & 708 & 18.0 & 1040 & $26.4^{*}$ & 3933 & 55.7 & ${ }^{*} P<0.05$ \\
\hline Female & 1886 & 60.4 & 633 & 20.3 & 604 & 19.3 & 3123 & 44.3 & \\
\hline \multicolumn{10}{|l|}{ Age (years) } \\
\hline $2-4$ & 1164 & 62.7 & 337 & 18.1 & 356 & 19.2 & 1857 & 26.3 & ${ }^{*} P<0.05$ \\
\hline $5-9$ & 1346 & 60.6 & 406 & 18.3 & 469 & 21.1 & 2221 & 31.5 & \\
\hline $10-13$ & 709 & 51.8 & 276 & 20.2 & 384 & $28.0^{*}$ & 1369 & 19.4 & \\
\hline 14-18 & 852 & 53.0 & 322 & 20.0 & 435 & $27.0^{*}$ & 1609 & 22.8 & \\
\hline \multicolumn{10}{|l|}{ Nationality } \\
\hline Saudi & 3222 & 57.5 & 1048 & 18.7 & 1329 & 23.7 & 5599 & 79.4 & NS \\
\hline Non-Saudi & 849 & 58.3 & 293 & 20.1 & 315 & 21.6 & 1457 & 20.6 & \\
\hline Total & 4071 & 57.7 & 1341 & 19.0 & 1644 & 23.3 & 7056 & 100.0 & \\
\hline
\end{tabular}

$N S=$ not significant .

Regarding distribution of weight categories by sex, our study showed that the overall rate of obesity among males was significantly higher than that among females (26.4\% versus $19.3 \%$ respectively) $(P<0.05)$. We also found that the percentage of obese males was significantly higher than that of overweight ones (26.4\% versus $18.0 \%$ respectively). The percentage of overweight females was significantly higher than the percentage of obese females ( $20.3 \%$ versus $19.3 \%$ respectively).

Comparison of the 3 weight categories by nationality showed no statistically significant difference in the rates of normal weight, overweight and obesity between Saudi and non-Saudi children.

Studying the distribution of weight categories among the children by age groups and sex revealed that more males than females were overweight in the age group 2-4 years (19.6\% versus $16.3 \%$ respectively). This was reversed in the age group 14-18 years, by which age the proportion of overweight females was higher than overweight males (23\% versus $16.7 \%$ respectively) (Figure 1 ).

The percentage of obese males was significantly higher than that among females in all age groups $(P<0.05)$.
Obesity in males showed a steady increase with age from $20 \%$ at ages $2-4$ years up to $35.6 \%$ at $14-18$ years, while in females the rate of obesity rose from $18.1 \%$ ages $2-4$ and peaked at ages $10-13$ years at $22.7 \%$ before declining at ages $14-18$ years to $19.2 \%$ (Figure 2 ). Thus by ages $14-18$ years $35.6 \%$ of males were obese versus $19.2 \%$ of females $(P<0.05)$.

\section{Discussion}

Obesity is one of the main concerns for health care worldwide. In 2001, the World Health Organization (WHO) announced that $10 \%$ of the world's children were obese and that the rate was rising in developing countries: 155 million children at school age were overweight, while 22 million under 5 years were overweight [9]. According to 2002 WHO statistics, there has been a broad shift in disease burden with the majority of deaths worldwide now being related to noncommunicable diseases, many of which can be linked to imbalances of nutrition, diet and physical activity [10].

In Saudi Arabia, many studies have been done to evaluate the magnitude of overweight and obesity among Saudi children (Table 3) [2,3,11-21]. It was found that overweight and obesity occurs in all provinces [21]. A recent study found that the Eastern province has the highest rates and the Southern province the lowest rates [3].

According to our study about 50\% of Saudi children in this Eastern province sample have a BMI above the $85 \%$ percentile. It was evident that Saudi children started developing overweight when they are 5-9 years of age- by which age $21 \%$ of children were overweight and $21 \%$ obese - and their weight continued to increase into the adolescent years. This could be attributed to the fact that children start going to school at that age, and hence, there is a less control on their eating habits and nutrition at this stage. Moreover, children in our country have become less active; few or none walk to school, spending more time in sedentary entertainment activities, such as viewing TV, computer and video games. On average, a child in Saudi Arabia spends 6 hours per day in front of screens [22]. Recent studies have found that a $2 \%$ increase in the prevalence of obesity has been documented for each extra hour per day 


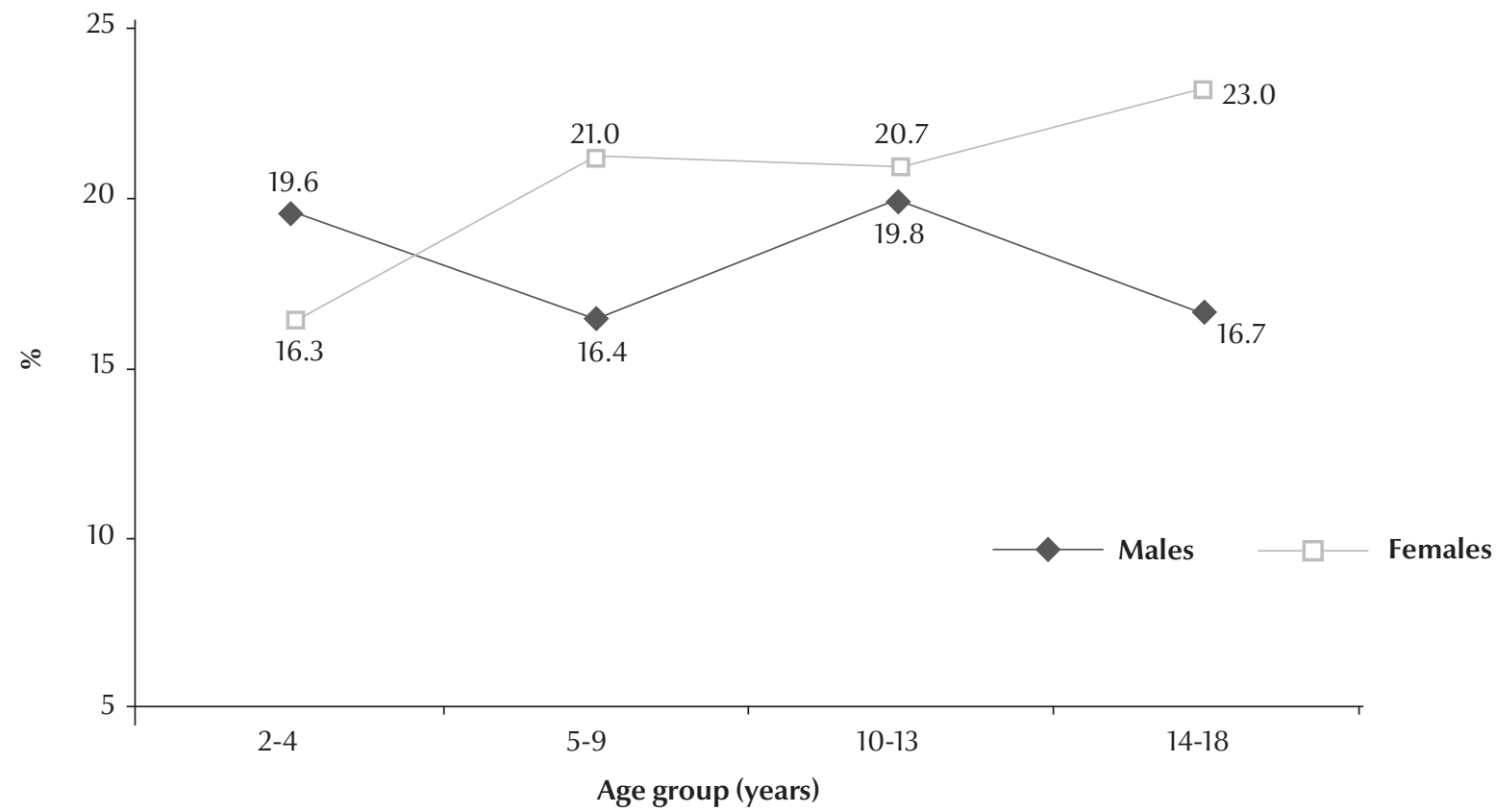

Figure 1 Distribution of overweight by age group and sex

of screen viewing by those aged $12-17$ years [22].

Our results agree with a previously published studyin the country that obesity in both sexes is low among preschool children (31\%) and highest among adolescents $(50 \%-76 \%)[2,20,21]$. In our sample, the peak of obesity was at age $10-13$ years $(28.0 \%)$ and stayed at the same high rate until age $14-18$ years. Studies have shown that $80 \%$ of obese adolescents become obese adults [8]. Adolescence has been described as the "critical period for the development for adult obesity" [23]. Hence, intervention before this age or is vital for both future health and the ability to sustain longterm weight control [22].
In our study, males showed a higher prevalence of obesity in all age groups, with a sharp rise at age 14-18 years. Females in this age group may be more self-conscious about their weight and avoid progressing into the obesity range. This is in accordance with a recent study conducted in Saudi Arabia which found that obesity was more common among

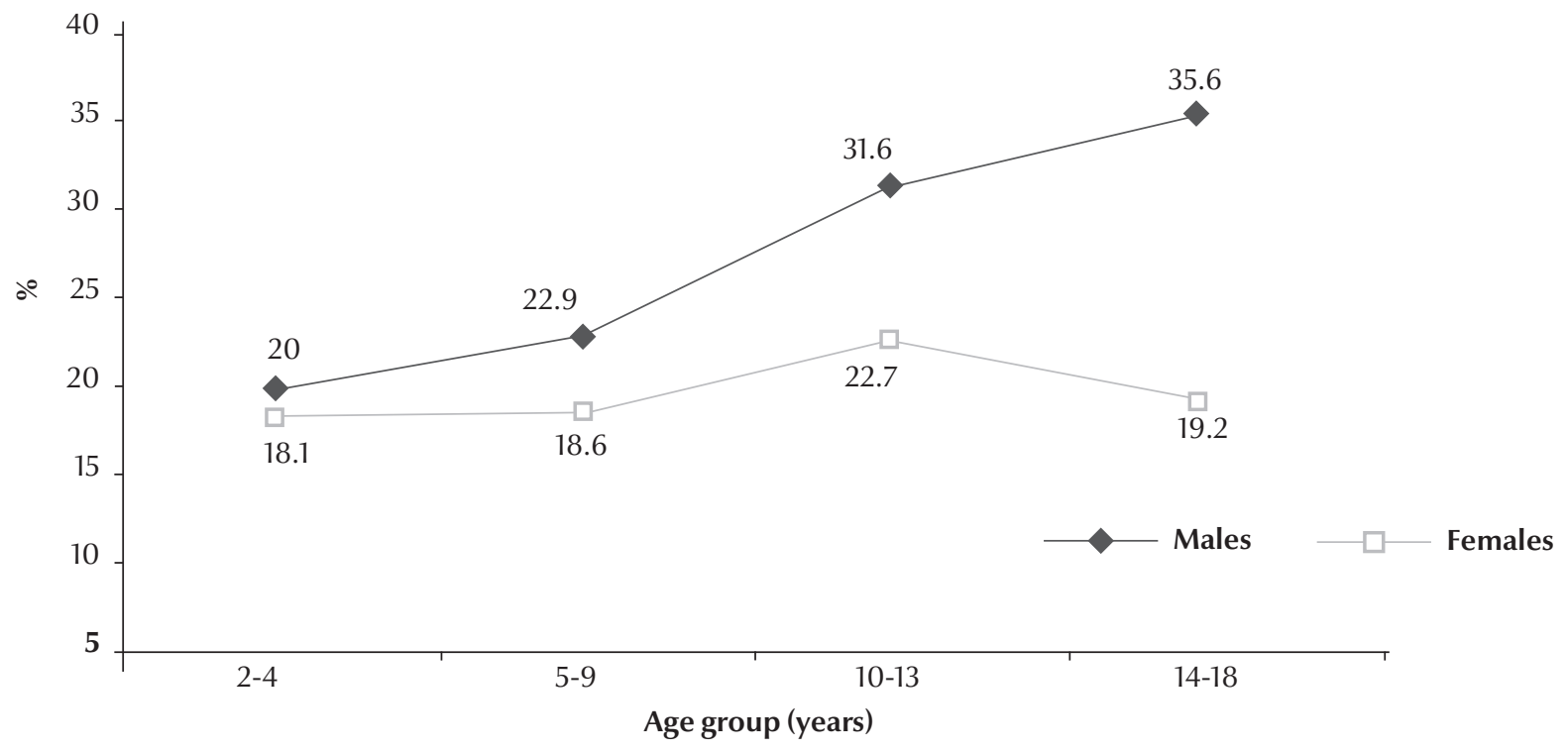

Figure 2 Distribution of obesity by age group and sex 
adolescent boys than was overweight. This was attributed to the lack of physical activity $[2,21]$ and to their ability to drive in our country which gives males easy access to unhealthy diets (e.g. fast foods that contain $40 \%-45 \%$ fat and soda drinks instead of water) and less time to eat at home where meals would be more nutritional $[9,20]$. With more mothers employed outside the home, traditional foods are replaced by fast foods and typically one-third of meals are eaten outside of the home environment, often at fast-food restaurants [22]. Studies have shown that the average consumption of sugar-sweetened beverages and fruit juices increased from $13 \mathrm{~g} /$ week in 1950 to $446 \mathrm{~g} /$ week in 1992/3 [24]. As recently as 1989-1991 to $1994-1995$, the consumption rose by $65 \%$ [22].

There was no significant difference in the prevalence of obesity among Saudi and non-Saudi children in our study, which draws attention towards the role of the environment, lifestyle and lack of physical activity as contributing factors over genetic factors in influencing the pattern of obesity [21]. A study of Saudi children in the Eastern province found that they were not engaged in sporting activities as much as their American counterparts $[21,25]$. Daily participation in physical education in highschool in the United States dropped from $42 \%$ in 1991 to $21 \%$ in 1999 . Furthermore, $60 \%-70 \%$ of urban inhabitants were living sedentary lives [22].

It is difficult to reduce excessive weight once it becomes established. Prevention of obesity in children should therefore start from birth by putting more emphasis on exclusive breastfeeding for the first 6 months of life. It is becoming a priority to establish preschool, school and adolescent health programmes, with the emphasis on increasing physical education hours and consumption of healthy food, by incorporating health messages into the school curricula [26]. 


\section{Conclusions}

In our sample $50 \%$ of children in the Eastern province of Saudi Arabia were overweight or obese $(\mathrm{BMI}>85$ th percentile). Our study showed that obesity started early in life (ages 10-14 years) and continued throughout the adolescent ages. The prevalence of obesity was higher among males than females, who had a tendency to be overweight rather than obese. Environmental factors may have more of an influence on the prevalence of obesity than do genetic factors. Interventions to encourage healthier lifestyles for children are needed at the national level.

\section{Acknowledgements}

The authors thank Hassan Amay (MBS Paediatrics) for her valued contribution to this article.

\section{References}

1. Reilly JJ. Descriptive epidemiology and health consequences of childhood obesity. Best Practice and Research Clinical Endocrinology and Metabolism, 2005, 19:327-341.

2. Al-Rukban MO. Obesity among Saudi male adolescents in Riyadh, Saudi Arabia. Saudi Medical Journal, 2003, 24:27-33.

3. El-Hazmi MA, Warsy AS. A comparative study of prevalence of overweight and obesity in children in different provinces of Saudi Arabia. Journal of Tropical Pediatrics, 2002, 48:172-177.

4. Statistics. Ministry of Education, Saudi Arabia [website] (http:// www.moe.gov.sa/openshare/englishcon/Statistics/Statisticsfor-the-year-1426H_1427H.htm_cvt.html, accessed 5 July 2010).

5. Pinhas-Hamiel $\mathrm{O}$ et al. Type 2 diabetes in childhood: not just for grown-ups anymore. Contemporary Pediatrics, 2001, 18:102-125.

6. Kuczmarski RJ et al. 2000 CDC growth charts for the United States: methods and development. Vital Health Statistics, 2002, 11:1-190.

7. Dehghan M, Akhtar-Danesh N, Merchant AT. Childhood obesity, prevalence and prevention. Nutrition Journal, 2005, 4:24.

8. Daniels SR et al. Overweight in children and adolescents: pathophysiology, consequences, prevention, and treatment. Circulation, 2005, 19, 111(15):1999-2012.

9. WHO global strategy on diet, physical activity and health. Resolution WHA55.23. Geneva, World Health Organization, 2004.

10. Barlow SE, Dietz WH. Obesity evaluation and treatment: Expert Committee recommendations. The Maternal and Child Health Bureau, Health Resources and Services Administration and the Department of Health and Human Services. Pediatrics, 1998, 102:E29.

11. Alam AA. Obesity among female school children in North West Riyadh in relation to affluent lifestyle. Saudi Medical Journal, 2008, 29:1139-1144.

12. Amin TT, Al-Sultan AI, Ali A. Overweight and obesity and their relation to dietary habits and socio-demographic characteristics among male primary school children in Al-Hassa, Kingdom of Saudi Arabia. European Journal of Nutrition, 2008, 47:310-318.

13. Al-Hazzaa HM. Prevalence and trends in obesity among school boys in Central Saudi Arabia between 1988 and 2005. Saudi Medical Journal, 2007, 28:1569-1574.
14. Al Turki YA. Overweight and obesity among attendees of primary care clinics in a university hospital. Annals of Saudi Medicine, 2007, 27:459-460.

15. Mahfouz AA et al. Obesity and related behaviors among adolescent school boys in Abha city, southwestern Saudi Arabia. Journal of Tropical Pediatrics, 2008, 54:120-124.

16. Farghaly NF et al. Lifestyle and nutrition and their impact on health of Saudi school students in Abha, Southwestern region of Saudi Arabia. Saudi Medical Journal, 2007, 28:415-421.

17. Al-Almaie SM. Prevalence of obesity and overweight among Saudi adolescents in Eastern Saudi Arabia. Saudi Medical Journal, 2005, 26:607-611.

18. Al-Saeed WY et al. Prevalence and socioeconomic risk factors of obesity among urban female students in Al-Khobar city, Eastern Saudi Arabia, 2003, Obesity Reviews, 2007, 8:93-99.

19. El-Hazmi MA, Warsy AS. A comparative study of prevalence of overweight and obesity in children in different provinces of Saudi Arabia. Journal of Tropical Pediatrics, 2002, 48:172-177.

20. Abahussain NA et al. Nutritional status of adolescent girls in the eastern province of Saudi Arabia. Nutrition and Health, 1999, 13:171-177.

21. Al-Nuaim AR, Bamgboye EA, Al-Herbish A. The pattern of growth and obesity in Saudi Arabian male school children. International Journal of Obesity and Related Metabolic Disorders, 1996, 20:1000-1005.

22. Baker $\mathrm{S}$ et al. Overweight children and adolescents: a clinical report of the North American Society for Pediatric Gastroenterology, Hepatology and Nutrition. Journal of Pediatric Gastroenterology and Nutrition, 2005, 40:533-543.

23. Steinbeck K. Childhood obesity. Treatment options. Best Practice and Research Clinical Endocrinology and Metabolism, 2005, 19:455-469.

24. Rennie $\mathrm{KL}$, Johnson $\mathrm{L}$, Jebb SA. Behavioural determinants of obesity. Best Practice and Research Clinical Endocrinology and Metabolism, 2005, 19:343-358.

25. Liu G. In the neighborhood: connecting plant biomass and childhood obesity. Contemporary Pediatrics, 2005, (May):14.

26. Al-Nozha MM et al. Obesity in Saudi Arabia. Saudi Medical Journal, 2005, 26:824-829. 